University for Business and Technology in Kosovo

UBT Knowledge Center

Nov 7th, 9:00 AM - 5:00 PM

\title{
Structural analysis of a typical highway bridge comparison between KTP, EN and AASHTO load models
}

Endrit Berisha

Epoka University, endritberisha1990@gmail.com

Follow this and additional works at: https://knowledgecenter.ubt-uni.net/conference

Part of the Civil Engineering Commons, and the Structural Engineering Commons

\section{Recommended Citation}

Berisha, Endrit, "Structural analysis of a typical highway bridge comparison between KTP, EN and AASHTO load models" (2015). UBT International Conference. 73.

https://knowledgecenter.ubt-uni.net/conference/2015/all-events/73

This Event is brought to you for free and open access by the Publication and Journals at UBT Knowledge Center. It has been accepted for inclusion in UBT International Conference by an authorized administrator of UBT Knowledge Center. For more information, please contact knowledge.center@ubt-uni.net. 


\title{
Structural analysis of a typical highway bridge comparison between KTP, EN and AASHTO load models
}

\author{
Endrit Berisha \\ Epoka University, Tirana, Albania \\ endritberisha1990@gmail.com
}

\begin{abstract}
This study consists on a structural analy sis comparison of a ty pical highway bridge between KTP, EN and AASHTO based on load cap acity. The Eurocodes are currently in the process of national implementation towards becoming the Europe wide means for structural design of civil engineering works. A team from Mott Macdonald inspected 562 bridges and the main causes of the defects are figured out in the study as traffic load, nature force, and aging, lack of maintenance and design deficiencies. As design codes are advancing with time, the need of Albania to upgrade its code has become a must. This paper presents the deficiencies of KTP when compared to the other design codes in order to help identify the areas which KTP is prone to problems and defects. A typical highway bridge with three spans $(60,80$ and $60 \mathrm{~m})$ was selected to be compared. CSi Bridge was used as the tool to do a structural analy sis of this bridge. The bridge was designed three times according to each code. Maximum moment is compared for the maximum load combinations of each code, on the columns and beams supporting the highway. Due to the design of the bridge the only members giving a cross-section of the load effect from the main deck are the one chosen. KTP is $40 \%-90 \%$ lower than EN and 20\%-80\% lower than AASHTO when compared for maximum moment at mid span of the beam and column. These refer to the biggest areas of deficiency KTP faces when compared with EN and AASHTO.
\end{abstract}

Keywords: KTP, EN, AASHTO, Road Bridge, CSi Bridge.

\section{Introduction}

In 1989 CEN/TC 250 was formed in charge of the development of the Eurocodes program which led to the first generation of Eurocodes in 1980s. The first EN Eurocode was published in 2002 and by 2007 all 58 parts were published. From March 2010 a wide implementation of the Eurocodes has started. Due to its high success and quality they have spread throughout the world and countries like Algeria, Lebanon, Liby a from Africa and countries like Indonesia, Philippines, Malaysia, Vietnam, Laos, Singapore, Thailand, My anmar, Brunei, Cambodia from Asia use them as their design codes to align with EN. The Eurocodes have entered its critical phase of implementation in the Balkans. Albania, Moldova and Turkey have not created National action plans, whilst fYRoM, Montenegro and Serbia have had a NAP for years. The translation has finished in fYRoM and Moldova; it is almost finished in Croatia (except EN1993 and EN1999), Serbia (except EN1992, EN1997 and EN1998). Albania has finished EN1990, EN1991, EN1992, EN1993 and 1998. Regarding the definition of NDPs (National Defined Parameters) the only country that has finished this process is Croatia. In Albania it has started for EN1998. In their first study cycle only Croatia and BiH use EN, whilst for the second cycle studies BiH, Croatia, fYRoM and Moldova use EN.

Study demonstrates that moving from country to country, condition change. For example comparing the flow of traffic of the Netherlands with Slovenia, it can be seen that the traffic volume and frequency is bigger in first. Even types of vehicles change, as bigger, heavier trucks are travelling more in the roads of the Netherlands than in Slovenia. Comparing EN with the RSA (Portuguese Code), SNiP (Russian Code), IAP (Spanish Code) proves that EN is the most conservative. Even when comparing EN with AASHTO (USA) and CSA (Canada) provides the same result as before. Building bridges in Albania dates back to antiquity. The period from early twentieth century until World War II is recognized as new era in the construction of bridges. For the first time began the use of pre-stressed bridges. One of the greatest achievements of this period was the construction of Zogu's 
Bridge (1938), one of the first in Europe with pre-stressed elements. During the 90s the country opened to the economy market and the road transportation system is characterized by a great development process. The overpass in Sukth, St. Vlash, Shkozet were built with pre-stress beams, the bridge in Mat was built with metal beams and concrete deck. The bridge at the entrance of Lezha is built with metal beams and monolithic deck.

At the moment design requirements are based on current regulations and national standards. It should be noted that most of them are actually quite old, a product of the latest revision of the code end 80s. The period before the 90 s was characterized by the ty pe of low masonry buildings, reinforced concrete columns. The rapid urbanization and the explosion of manufacture buildings characterized the period after the 90s. An improved design control and construction of structural works, and a better communication between EU members would be the result of the adaptation. From the institutional point of view, the management of the adoption of the Eurocodes will be supervised by the Technical Committee that was established in Tirana.

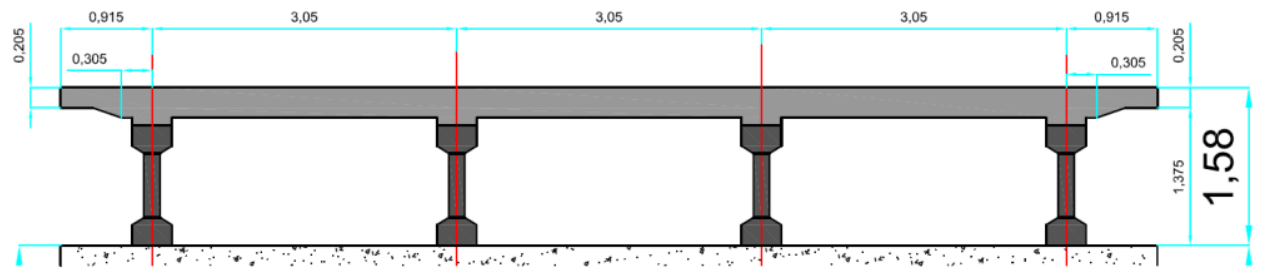

Figure 2 Cross-Section of the Bridge

\section{Methodology}

A general model of a bridge is chosen based on average length given by recent studies. A typical bridge was chosen because choosing an existing bridge would need further details about the aging of components, further testing and will not provide a fair comparison of the codes. The bridge has three spans: 60,80 and $60 \mathrm{~m}$. It is designed by CSi Bridge comparing the design loads of KTP, EN and AASHTO. As the loads are applied and after the bridge is subjected to different combinations and comparison of moment and shear is done. The comparison is done for the middle section of the left span, middle section of the middle span, middle section of the right span and for the middle section of the columns. These points are chosen as being the most critical points of the bridge.

The width of the bridge is $11 \mathrm{~m} ; 5.5 \mathrm{~m}$ is divided into $3.5 \mathrm{~m}$ for the lane, $1 \mathrm{~m}$ for the sidewalk and $1 \mathrm{~m}$ for the parapet. The bridge is $10 \mathrm{~m}$ high. It contains continuous beams, $25 \mathrm{~cm}$ thick slab, abutments and piers. The deck is designed to have two internal girders.

The minimum temperature considered for shadow areas is $-20^{\circ} \mathrm{C}$. The return period of this is 100 years (meteorological institute of Tirana). The maximum temperature in the shadow area is considered to be $40^{\circ} \mathrm{C}$. The difference between the concrete slab temperature and steel part was taken to be not more than $10^{\circ} \mathrm{C}$. The ambient relative humidity is assumed to be taken as $80 \%$. These statistics explain why no temperature change effect has been taken into account in the design. At the bridge spans over a field and underneath lays a highway, there are few obstacles, like some houses or trees. No settlement is taken in account to happen.

\section{Results}

After the analy sis has finished, the bridge loads have been compared. The differences between KTP, AASHTO and EN have been described in the tables below. The analysis is conducted separately for each design code, taking into account the design loads, and load combination of each one. The comparison is done for element frames. For the element frames, two columns and the beam over them, which comprise the bridge bent, are taken. Maximum shear and moment are compared. Below figure 2 illustrates the location of this point and elements. The comparison is done for shear, moment on the column, and beam. Figures 3 and 4 are for the column, while figures 5 and 6 are for the beam. 


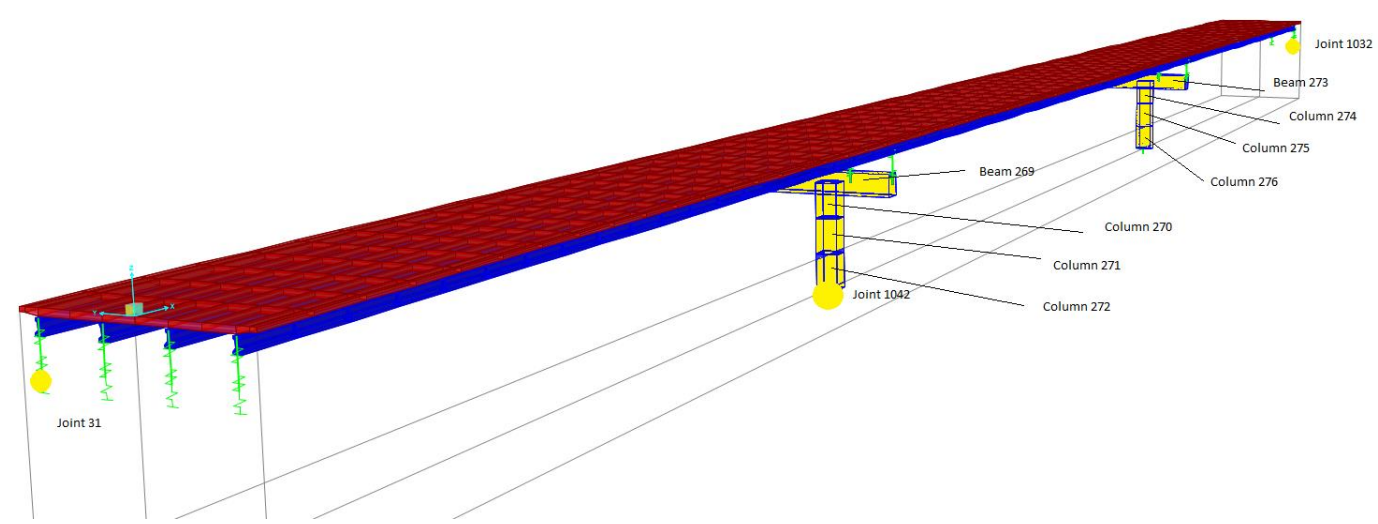

Figure 2 Location of Joints and members taken into account

\section{Column}

Figures 3 and 4 are for the column. Graph 3 it can be seen that in the case of KTP shear is much lower than in the cases of other codes. Shear force for the Eurocode is greater than AASHTO; this comes mostly because of the load models used. Eurocode takes into account bigger loads and therefore the shear is bigger. The model of KTP is design for $200 \mathrm{kN}$ shear force, AASHTO is designed for approximately $400 \mathrm{kN}$, and Eurocode is designed for approximately $580 \mathrm{kN}$.

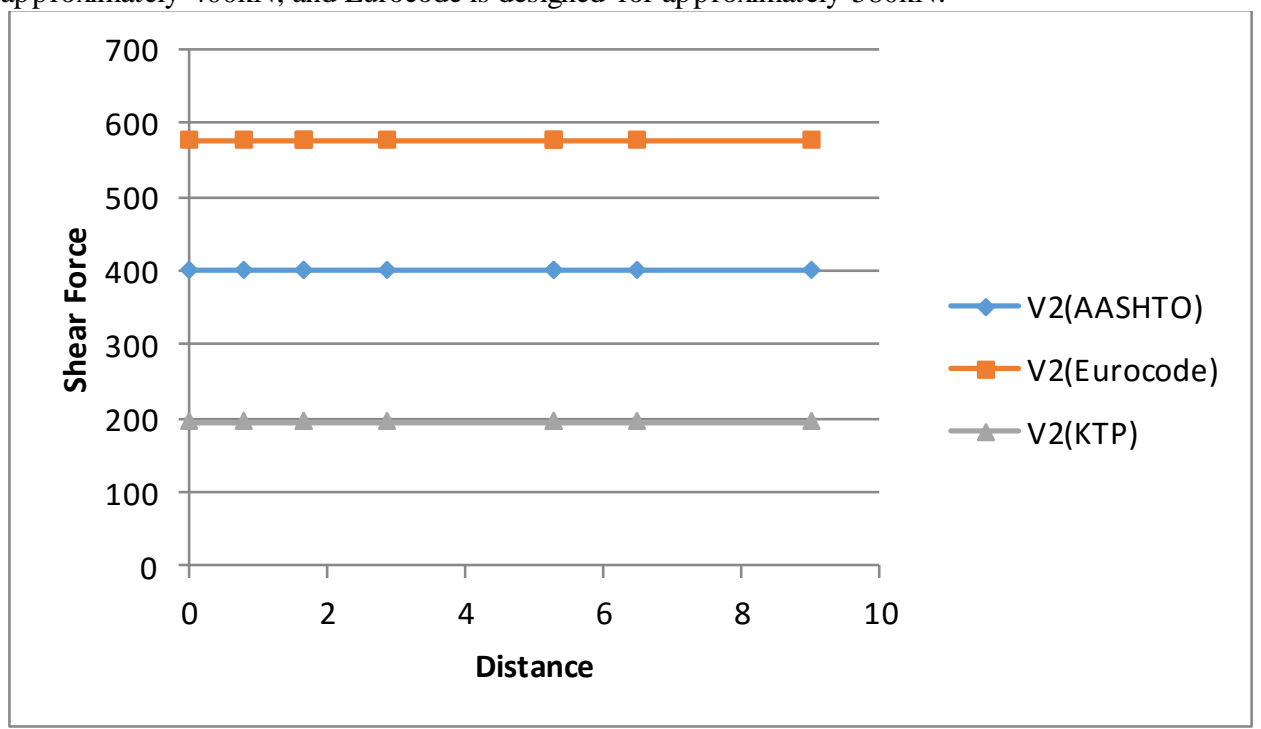

Figure 3 Graph of the variation maximum of shear for the column

At the graph it can be seen that in the case of KTP shear is much lower than in the cases of other codes. Shear force for the Eurocode is greater than AASHTO this comes mostly because of the load models used. Eurocode takes into account bigger loads and therefore the shear is bigger. The model of KTP is design for $200 \mathrm{kN}$ shear force, AASHTO is designed for approximately $400 \mathrm{kN}$, and Eurocode is designed for approximately $580 \mathrm{kN}$. 
International Conference on Civil Engineering, Infrastructure and Environment, Nov 2015

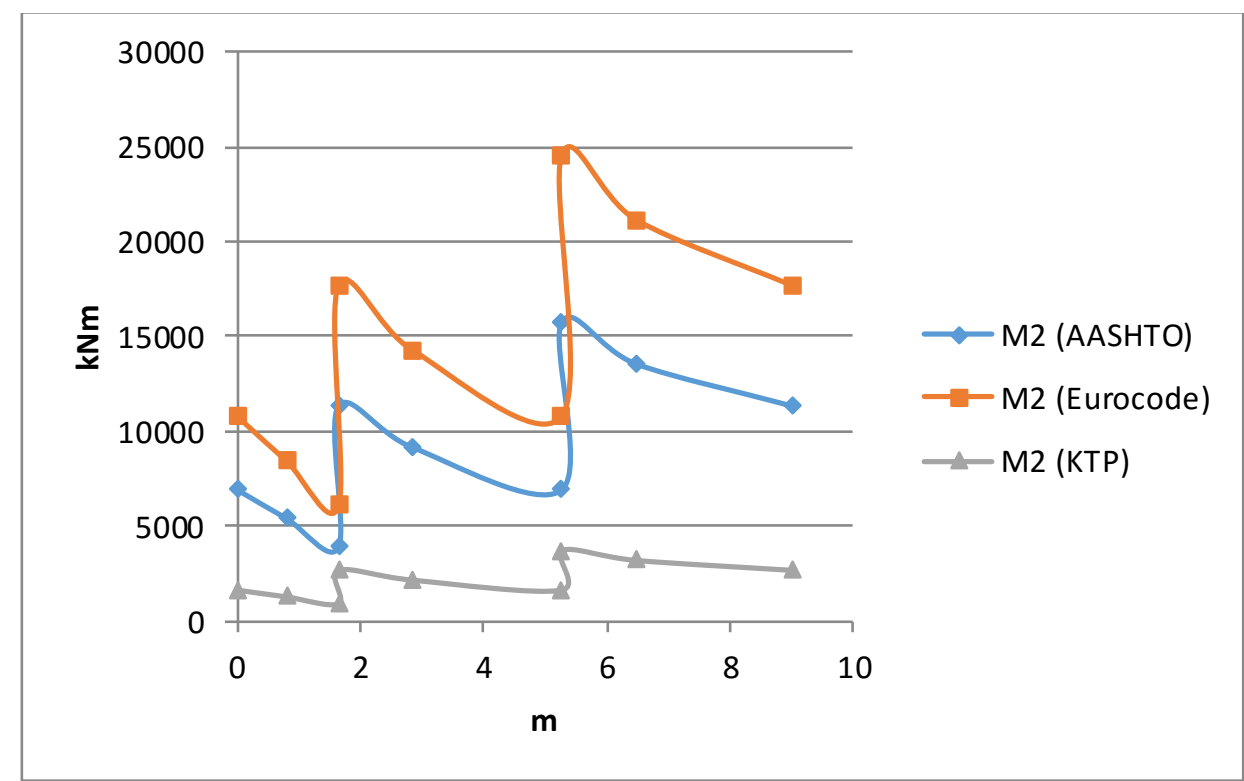

Figure 4 Graph of variation of maximum moment for the column

When comparing maximum moment, the results give the same conclusion as the ones before. Eurocode due to its model load inflicts a bigger moment on the structure. Maximum moment for EN is $23594.14 \mathrm{kN} / \mathrm{m}, 15762.45 \mathrm{kN} / \mathrm{m}$ for AASHTO and $3721.72 \mathrm{kN} / \mathrm{m}$ for KTP. All these results are due to the lack of input needed to design according to KTP, As AASHTO and Eurocode design taking into account earthquake forces and wind, which are not inputted on the KTP.

\section{Beam}

The graphs below express relation between the codes for the beam.

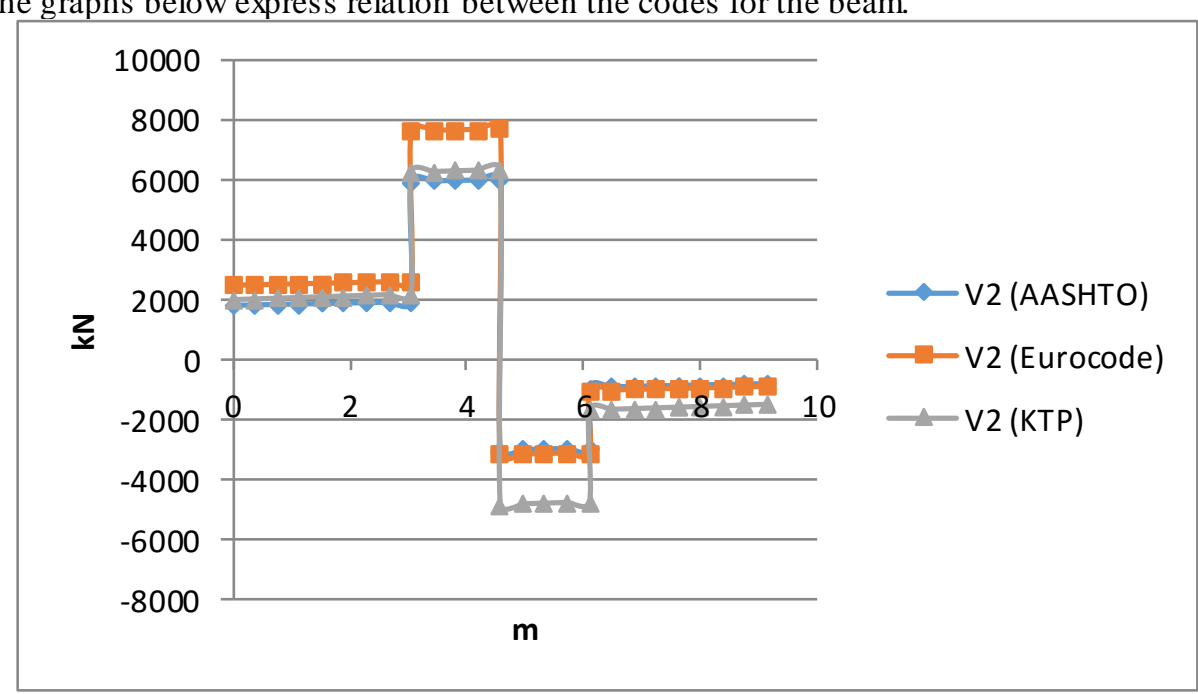

Figure 5 Graph for the variation of maximu $m$ shear for the beam

Figure 5 gives the relation of shear for the three codes. Eurocode has bigger shear acting on the beam, with AASHTO and KTP giving similar results. AASHTO gives a shear of 5986kN; Eurocode has a maximum shear of $7679 \mathrm{kN}$, and KTP $6325 \mathrm{kN}$. Figure 6 provides the moment acting on the beam. As 
it can be easily understood the biggest moment acts in the mid span. The biggest moment is subjected by the Eurocode with a value of $5958 \mathrm{kNm}$, with AASHTO having a moment of $4096 \mathrm{kNm}$, and KTP $3273 \mathrm{kNm}$.

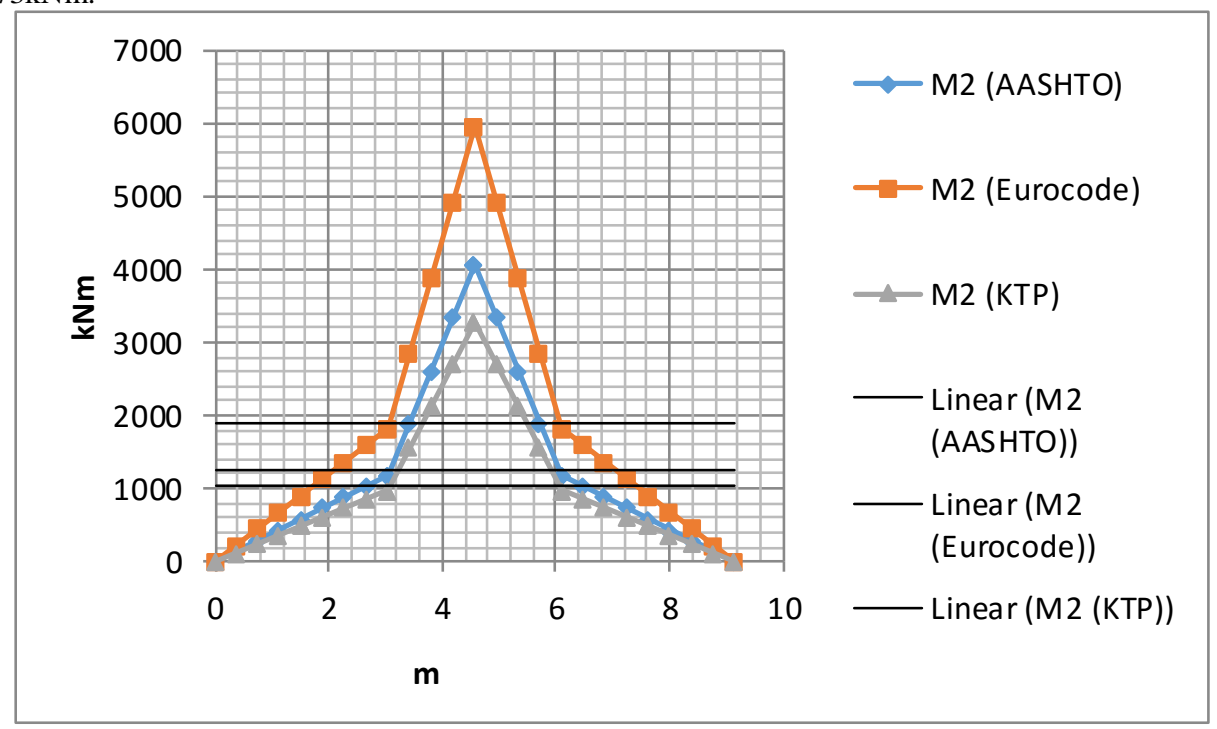

Figure 6 Graph for the variation of maximum moment for the beam

\section{Conclusion}

Design codes have improved from the time of construction of most of the bridges in Albania. Requirements for safety, calculation and construction techniques have advanced. All the experience from failures around the world have been collected and summarized in literatures and strict design codes. The advancement of design codes has been symmetrical with the population growth. This explains why the capacity of bridge before 50 y ears is much lower than the ones constructed today. From previous researches and comparisons done, the Portuguese Code, The Russian Code and Spanish Code all are designed with lower requirements than the Eurocode. Even in the case of KTP the results show the same conclusion. From the information provided by KTP, when calculating load capacity the effect of wind and earthquake loads are not taken into account. This limits the ability of the superstructure to withstand lateral loads and be prone to deficiency in bending moment and shear. Further detailed testing needs to be done in order to understand the life of each structure, as none has been constructed the same way. This thesis provides a structural analy sis of a bridge comparing KTP, EN and AASHTO based on load capacity. Other problems can be found when comparing the methods of construction, the materials used and calculations done. Both cases for beams and columns shown in the result give that:

For beams:

KTP is $17.6 \%$ lower than EN and 5.66\% bigger than AASHTO when compared for shear capacity. KTP is $45 \%$ lower than EN and $20 \%$ lower than AASHTO when compared for maximum moment. For columns:

KTP is $65 \%$ lower than EN and 50\% lower than AASHTO when compared for shear capacity. $\mathrm{KTP}$ is $84.25 \%$ lower than EN and $76.4 \%$ lower than AASHTO when compared for maximum moment.

The results found provide the areas where the bridges in Albania suffer the most, providing also the areas where the strengthening needs to be performed in order to meet requirements imposed by EN. As Albania is a candidate for the European Union it needs to follow the standards it imposes. This thesis provides the background where the first steps need to be taken for the upgrade to happen. 


\section{Reference}

1. Bridge Loads, Colin O'Connor, (2000).

2. $\quad$ En 1991 En 1991-2 Traffic Loads Traffic Loads On Bridges On Bridges

3. Ktp (Pg $23-78)$, (1978).

4. Aashto Lrfd Bridge Design Specifications, $4^{\text {th }}$ Edition, (2007).

5. Adoption Of The Eurocodes Outside The E.U. (Malcolm Greenley, Program Manager, Bsi Department - Construction And The Built Environment)

6. Adoption Of The Eurocodes In The Balkan Region, Jrc Enlargement And Integration Action, Roberta Apostolska, Fabio Taucer, Silvia Dimova And Artur Pinto, (2014).

7. Bridge Assessment Loading: A Comparison Of West And Central/East Europe by Eugene J. Obrien, Professor Of Civil Engineering, University College Dublin, Earlsfort Terrace, Dublin 2, Ireland; Colin C. Caprani, Phd Researcher, Dept. Of Civil Engineering, University College Dublin, Earlsfort Terrace, Dublin 2, Ireland; Gavin J. O'connell, Mengsc Student, Dept. Of Civil Engineering, University College Dublin, Earlsfort Terrace, Dublin 2, Ireland, (03.2006)

8. Reliability Analy sis Of Pre-Stressed Concrete Bridge Girders: Comparison Of Eurocode, Spanish Norma Iap And Aashto Lrfd, By Andrzej S. Nowak, Chan-Hee Park And Juan R. Casas (2002)

9. Service Life Assessment Of Existing Highway Bridges With No Planned Regular Inspections By Alp Carter, P.E., Asce, A. Melih Yanmaz, Etc...(2008)

10. Comparison of Russian Norms (Snips) And European Norms (Eurocodes) For Road And Railway Bridge, Anastasia Lukianenko, 2012.

11. Structural Analy sis of Concrete Bridge Decks: Comparison between the Portuguese Code (Rsa) And The Eurocode Road Load Models, João Nuno Taborda Brás Robalo, (2013).

12. Bridge Design To Eurocodes Worked Examples, Y. Bouassida, E. Bouchon, P. Crespo, P. Croce, L. Davaine, S. Denton, M. Feldmann, R.Frank, G.Hanswille, W. Hensen, B. Kolias, N. Malakatas, G. Mancini, M. Ortega, J. Raoul, G. Sedlacek, G. Tsionis, (4- 6 October 2010).

13. Bridge Assessment in Albania by Mott MacDonald, (2011)

14. Instituti Meteoroligik Shqiptar. Retrieved from: http://www.akti.gov.al/kerkimishkencor/institucione_ash/ihm.html

15. Introduction To Csi Bridge, (2011). Retrieved From: Https://Wiki.Csiamerica.Com/Display/Csibridge/Home 